Goldschmidt 2021 Abstract

https://doi.org/10.7185/gold2021.6450

\section{Nucleation and growth of spherulites in coral skeletons, aspirin, chocolate}

\author{
PUPA GILBERT ${ }^{1}$, CAYLA A STIFLER ${ }^{1}$ AND LASZLO \\ GRANASY $^{2}$
}

${ }^{1}$ UW-Madison

${ }^{2}$ Wigner Institute of Physics

Presenting Author: pupa@physics.wisc.edu

Spherulites are radial distributions of acicular crystals, common in biogenic, geologic, and synthetic systems [1], yet exactly how spherulites nucleate and grow is still poorly understood. To investigate these processes, as a model system we chose corals, which are well known to form their skeletons from aragonite $\left(\mathrm{CaCO}_{3}\right)$ spherulites [2], and because a comparative study of crystal structures across coral species has not been done previously. We observed that all 12 diverse coral species analyzed here exhibit plumose spherulites in their skeletons, with well-defined centers of calcification ( $\mathrm{CoCs}$ ), and crystalline fibers radiating from them. In 7 of the 12 species, we observed a skeletal structural motif not observed previously: randomly oriented, equant crystals, which we termed "sprinkles". In 1 species, sprinkles are localized at the CoCs, while in 6 other species sprinkles are either layered at the growth front (GF) of the spherulites, or randomly distributed [3]. Based on these observations, we conclude that spherulites form by growth front nucleation (GFN) of randomly oriented sprinkles, competition for space, and coarsening produce spherulites, rather than the previously assumed slightly misoriented nucleations termed "non-crystallographic branching". Phase-field simulations support this mechanism, and, using a minimal set of thermodynamic parameters, are able to reproduce all of the microstructural variation observed experimentally in all coral skeletons. Beyond coral skeletons, other spherulitic systems including aspirin, metals, and chocolate are predicted to form by GFN of sprinkles, followed by coarsening.

[1] C.-Y. Sun, M.A. Marcus, M.J. Frazier, A.J. Giuffre, T. Mass, P.U. Gilbert, Spherulitic growth of coral skeletons and synthetic aragonite: Nature's three-dimensional printing, ACS Nano 11 (2017) 6612-6622.

[2] C.-Y. Sun, C.A. Stifler, R.V. Chopdekar, C.A. Schmidt, G. Parida, V. Schoeppler, B.I. Fordyce, J.H. Brau, T. Mass, S. Tambutté, P.U.P.A. Gilbert, From particle attachment to spacefilling coral skeletons Procs Natl Acad Sci 117(48) (2020) 30159-30170.

[3] C.-Y. Sun, L. Gránásy, C.A. Stifler, T. Zaquin, R.V. Chopdekar, N. Tamura, J.C. Weaver, J.A.Y. Zhang, S. Goffredo, G. Falini, M.A. Marcus, T. Pusztai, V. Schoeppler, T. Mass, P.U.P.A. Gilbert, Crystal nucleation and growth of spherulites demonstrated by coral skeletons and phase-field simulations, Acta Biomaterialia 120 (2021) 277-292.

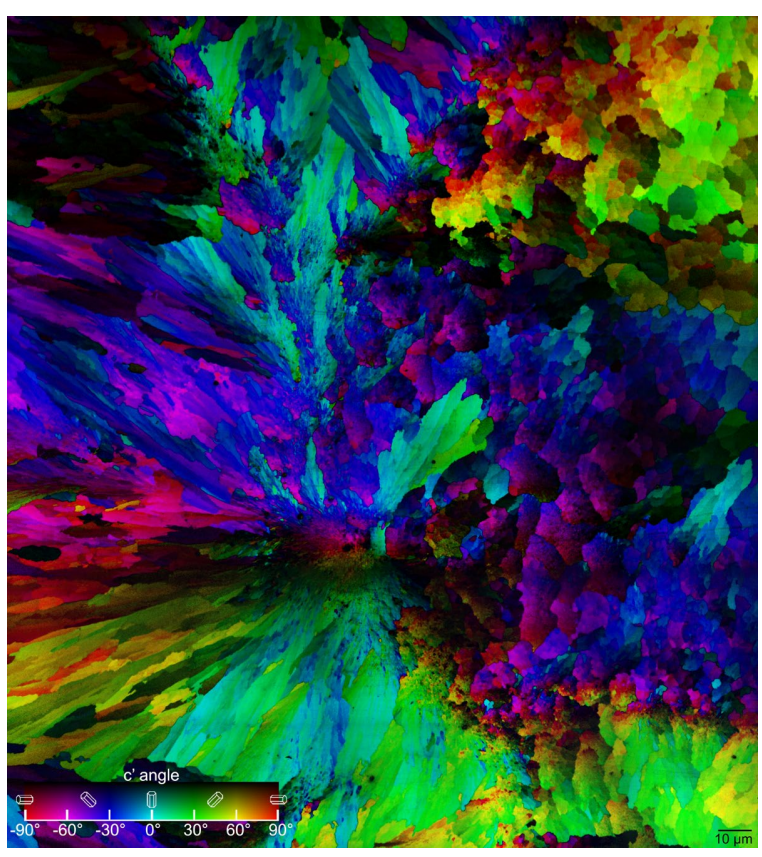

